\title{
Analysis of Thermal-Mechanical Coupling of Automotive Disc Brake Based on Numerical Simulation Method
}

\author{
Kuiyang Wang* and Jinhua Tang
}

School of Automotive and Traffic Engineering, Jiangsu University of Technology, Changzhou, 213001, China

\begin{abstract}
The background and necessity of application of numerical simulation method in research on friction materials of automotive brake are analyzed. The numerical analysis methods of conversion of braking energy, distribution of friction heat, transfer of friction heat and thermal mechanical coupling, are discussed. The dynamic temperature field and thermal stress field of the same brake disc and two kinds of friction plates of different materials, which are the composite materials based on resin and the powder metallurgy based on copper, are simulated and analyzed respectively under emergency braking. The effect of friction materials' performance on friction temperature and thermal stress distribution is obtained. The results show that the friction performance of composite materials based on resin is better than the powder metallurgy based on copper. The results are consistent with the experimental results. The numerical simulation methods proposed have a good predictive effect on the typical characteristics of friction materials in the process of braking, which provides effective references for preparation and optimization design of friction materials of brake.
\end{abstract}

Keywords: Automotive brake, Friction material, Numerical simulation, Thermo-mechanical coupling, Finite element analysis.

\section{INTRODUCTION}

Through friction motion, the friction materials of brake can convert the kinetic energy and potential energy of vehicle into thermal energy, and make vehicle to be decelerated or parked. It's performance directly affects the braking performance and safety performance of vehicle. The braking process involves kinetics, thermodynamics, tribology, material science, etc., and the normal load, sliding speed, temperature and surface stress of friction materials all effect the braking performance. The traditional experimental methods, not only will cause a waste of both time and energy, but also sometimes even make it difficult to obtain some characteristics information of friction materials in braking process, such as the friction materials' parameters for stress, strain and temperature etc. Therefore, it is necessary to apply the numerical simulation method to the study of friction materials, give full play to the advantages of computer simulation technology, and compensate for the lack of traditional experimental methods.

In the high strength braking process, the temperature of brake's friction materials will be rapidly increased, which can lead to a series of physical and chemical changes on the surface of friction materials. The mechanical properties and wear resistance of friction materials will drop sharply, and it will lead to dangerous heat fading phenomenon [1]. Because of the common existence of this situation in friction materials, the thermal behavior and mechanical behavior of friction materials during braking are necessary to study. In this paper, based on the theory of finite element analysis and the theory of thermodynamics, according to the structure param-

*Address correspondence to this author at the No. 1801, Zhongwu Road, Changzhou, China. Postcard: 213001; Tel: +8613861040832; E-mail: wkuiy@126.com eters of selected vehicle, the change regulation and coupling of dynamic temperature field and thermal stress field of brake's friction materials are analyzed in the process of braking by using the method of numerical simulation. The changes of stress, strain and temperature are analyzed comparatively between two different friction materials, which provides theoretical reference for selection and optimal design of friction material.

\section{THEORETICAL BACKGROUND OF FRIC- TION HEAT}

\subsection{Calculation of Thermal Load}

In the process of braking, the tires and brakes can produce frictional resistance. Ignoring some secondary factors such as air resistance, a part of braking energy is absorbed by brakes, and the other part of braking energy is dissipated by the friction between tires and ground. The total braking energy of vehicle in this time is shown as follows.

$\mathrm{Q}=\frac{m}{2}\left[\left(\frac{v_{1}}{3.6}\right)^{2}-\left(\frac{v_{2}}{3.6}\right)^{2}\right]$

where $\mathrm{m}$ is the total mass of automobile, $\mathrm{v}_{1}$ is the initial velocity and $\mathrm{v}_{2}$ is the final velocity.

Hypothesis, the slip rate between tire and road is s, then the braking energy consumed by tires is shown as follows.

$\mathrm{Q}_{\mathrm{t}}=Q \cdot s=\frac{m}{2}\left[\left(\frac{v_{1}}{3.6}\right)^{2}-\left(\frac{v_{2}}{3.6}\right)^{2}\right] \cdot s$

The braking energy absorbed by brakes is shown as follows.

$\mathrm{Q}_{\mathrm{b}}=Q \cdot(1-s)=\frac{m}{2}\left[\left(\frac{v_{1}}{3.6}\right)^{2}-\left(\frac{v_{2}}{3.6}\right)^{2}\right] \cdot(1-s)$ 
Hypothesis, the energy absorbed is evenly distributed on the four brakes. Since there are two friction surfaces for each brake, the friction heat of single friction surface is as follows:

$\mathrm{Q}_{\mathrm{c}}=Q_{\mathrm{b}} / 8=\frac{m}{16}\left[\left(\frac{v_{1}}{3.6}\right)^{2}-\left(\frac{v_{2}}{3.6}\right)^{2}\right] \cdot(1-s)$

According to the definition of heat flux density, the relationship between friction heat and heat flux density can be expressed by the following formula [2].

$\mathrm{q}=\frac{d Q_{c}}{d t} / S$

where $\mathrm{q}$ is the heat flux density, $\mathrm{t}$ is the braking time and $\mathrm{S}$ is the contact area of friction surface.

Accordingly, the relationship between heat flux density and braking time is shown below.

$\mathrm{q}=-\frac{2 m(1-s)}{16 \times 3.6^{2} \times S}\left(a^{2} t+v_{1} a\right)=-\frac{0.00965 m(1-s)}{S}\left(a^{2} t+v_{1} a\right)$

where $\mathrm{a}$ is the braking deceleration.

In the analysis of braking heat, it is generally assumed that the average temperature between contact surfaces is equal and the heat flux is continuous [3]. Hypothesis, the heat flux density inputted to friction plate and brake disc is $q_{f}, q_{d}$ respectively, then the relationship between $q_{f}$ and $q_{d}$ is shown as follows.

$\mathrm{q}=q_{d}+q_{f}, \mathrm{~K}_{\mathrm{q}}=\frac{q_{d}}{q_{f}}=\left(\frac{\lambda_{d} c_{d} \rho_{d}}{\lambda_{f} c_{f} \rho_{f}}\right)^{2}$

Where $\lambda_{\mathrm{d}}, \mathrm{C}_{\mathrm{d}}$ and $\rho_{\mathrm{d}}$ are coefficients of thermal conductivity, specific heat capacity and density of brake disc respectively, and $\lambda_{\mathrm{f}}, \mathrm{C}_{\mathrm{f}}$ and $\rho_{\mathrm{f}}$ are coefficients of thermal conductivity, specific heat capacity and density of friction plate respectively.

According to Eq. 7, it can be obtained:

$\mathrm{q}_{f}=\frac{q}{1+K_{q}}, \mathrm{q}_{d}=\frac{K_{q} q}{1+K_{q}}$

Because there is thermal resistance of contact between the rough contact surfaces, there are some differences between average temperature of friction surface calculated according to above hypothesis and the result obtained by actual measurement. In order to avoid the above error, it is deemed that the friction heat is produced in the surface of friction material. For friction materials, the heat flow directly enters their bodies; for brake discs, the heat flow enters their bodies through some thermal resistances produced by heat conduction. After being distributed into brake disc and friction plate, the heat generated by friction dissipates in each component of brake and its surrounding air. The degree of heat dissipation directly affects the temperature rise of brake.

\subsection{Theoretical Background of Heat Transfer}

Heat transfer includes heat conduction, heat radiation and heat convection in three ways [4]. Each way has different characteristic, mathematical analysis and description method.
The way of heat conduction refers to the heat conduction phenomenon caused due to the thermal motion of microscopic particles between the surface and inner part of contacting objects. The heat conduction is characterized by heat transfer from high temperature object to low temperature object. The basic law of Friyege heat conduction points out that the size of heat flow density is proportional to the absolute value of temperature gradient, and its direction is in contrast with the temperature gradient direction. It is shown as follows.

$\mathrm{q}=-K \frac{\partial T}{\partial n}$

where the thermal conductivity is $\mathrm{K}$, the outer normal direction of cutting plane is $n$, and material temperature is $T$.

The heat transfer through radiation is called heat radiation. The main characteristic of heat radiation is that it does not need a substance medium. The Stephen Boltzmann Law points out that the maximum energy density of surface radiation is proportional to the biquadratic of temperature. It is shown as follows.

$\mathrm{q}^{\mathrm{r}}=\sigma \cdot T_{S}^{4}$

where $\sigma$ is the Stephen Boltzmann constant (5.67X10$\left.8 \mathrm{~W} /\left(\mathrm{m}^{2} \cdot \mathrm{K}^{4}\right)\right)$, and $\mathrm{T}_{\mathrm{s}}$ is the absolute temperature of surface. The surface described in Eq. 10 is the so-called blackbody, and the radiation heat flux of real surface is normally described according to Eq. 11.

$\mathrm{q}^{\mathrm{r}}=\sigma \cdot \varepsilon \cdot T_{S}{ }^{4}$

where $\varepsilon$ is the surface emissivity, and its value is between 0 and 1 .

The way of heat convection refers to the heat transfer between the fluid and solid surfaces. The calculation formula of heat convection from Newton cooling formula is shown as follows.

$\mathrm{q}=h \cdot\left(T_{w}-T_{f}\right)$

where $\mathrm{h}$ is the transfer coefficient of heat convection $\left(\mathrm{W} /\left(\mathrm{m} \cdot{ }^{\circ} \mathrm{C}\right)\right), \mathrm{T}_{\mathrm{w}}$ is the temperature of solid wall, $\mathrm{T}_{\mathrm{f}}$ is the mainstream temperature of fluid wall.

\subsection{Theoretical Background of Thermal Mechanical Coupling}

The research on thermal mechanical coupling field of brake friction includes heat conduction, stress, strain and all kinds of complex boundary conditions of brake disc and friction plate. According to the principle of heat transfer, the 3D transient heat conduction equation of brake disc and friction plate can be obtained [5].

$k\left(\frac{\partial^{2} T}{\partial x^{2}}+\frac{\partial^{2} T}{\partial y^{2}}+\frac{\partial^{2} T}{\partial z^{2}}\right)+q_{V}=\rho c \frac{\partial T}{\partial t}$

where $\mathrm{k}$ is heat conduction coefficient $\left(\mathrm{W} /\left(\mathrm{m} \cdot{ }^{\circ} \mathrm{C}\right)\right)$, $\mathrm{T}$ is temperature $\left({ }^{\circ} \mathrm{C}\right), \mathrm{q}_{\mathrm{v}}$ is the heat flow per unit time $(\mathrm{J} / \mathrm{s}), \rho$ is density of material $\left(\mathrm{Kg} / \mathrm{m}^{3}\right), \mathrm{c}$ is specific heat at constant pressure of material $\left(\mathrm{J} /\left(\mathrm{Kg} \cdot{ }^{\circ} \mathrm{C}\right)\right)$, and $\mathrm{t}$ is braking time $(\mathrm{s})$.

Before brake starts working, the temperature of friction material is equal to environmental temperature. After brake starts work, because the friction plate clings to brake disc 
under certain pressure, a lot of friction heat is produced. Among them, most of the heat is absorbed by friction surface of brake disc. With the rise in temperature of brake disc, the heat conduction, heat convection and heat radiation are produced in the interior of brake disk and each interface.

Therefore, the boundary conditions of numerical analysis are determined as follows.

In the initial time:

$T(x, y, z)=T_{0}$

Frictional contact surface:

$-\lambda \frac{\partial T}{\partial z}=-q+a_{z}\left(T-T_{0}\right)+\varepsilon_{z} \sigma\left(T^{4}-T_{0}^{4}\right)$

Heat exchange surface:

$-\lambda \frac{\partial T}{\partial n_{i}}=a_{i}\left(T-T_{0}\right)+h_{i} \sigma\left(T^{4}-T_{0}^{4}\right)$

where $T_{0}$ is environmental temperature, $n_{i}$ is unit normal vector of each interface, $\mathrm{z}$ is unit normal vector of friction interface, $\alpha_{i}$ is coefficient of heat convection of each interface, $\alpha_{z}$ is coefficient of heat convection of friction interface, $h_{i}$ is coefficient of radiation heat of each interface, $\varepsilon_{z}$ is coefficient of radiation heat of friction interface, and $\mathrm{q}$ is heat flux density absorbed by brake disc.

In the process of braking, the friction plate is subject to axial constraint of brake disc and piston. At the same time, the brake disc is subject to axial constraint of wheel and friction plate. And the change of temperature field is not symmetrical. Therefore, a lot of heat stress will be produced in the process of braking. The linear strain and stress caused, considering the effect of temperature, are shown as follows.

$\varepsilon=\alpha\left(T-T_{0}\right)$

$\sigma=D\left(\varepsilon-\varepsilon_{0}\right)$

where $\alpha$ is the linear expansion coefficient of material, $\varepsilon_{0}$ is the initial strain caused by the temperature change of material, $\varepsilon$ is the strain matrix of material, $\sigma$ is the stress matrix of material, and $\mathrm{D}$ is the elastic matrix of material.

\section{FINITE ELEMENT ANALYSIS FOR THER- MAL MECHANICAL COUPLING}

\subsection{Geometry Model of Brake}

The part parameters of vehicle selected are as follows: the total mass of vehicle fully loaded is $1798 \mathrm{~kg}$; the wheel- base is $2715 \mathrm{~mm}$; the rolling radius of tire is $317 \mathrm{~mm}$; the outer diameter, inside diameter and thickness of brake disc are $256 \mathrm{~mm}, 65 \mathrm{~mm}$ and $12.5 \mathrm{~mm}$ respectively; the outer diameter, inside diameter, thickness and wrap angle of friction plate are $250 \mathrm{~mm}, 154 \mathrm{~mm}, 14.3 \mathrm{~mm}$ and $66^{\circ}$ respectively. The simplified geometric model of brake drawn out is shown in Fig. (1).

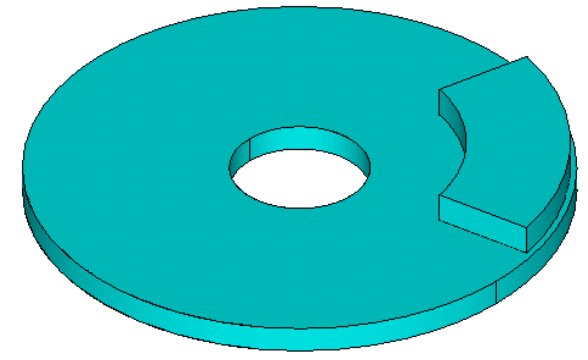

Fig. (1). Geometry model of brake.

\subsection{Property Parameters of Materials}

In this paper, ZG1Cr13 is selected as the material of brake disc; the composite materials based on resin is selected as the material of friction plate 1; the powder metallurgy based on copper is selected as the material of friction plate 2 . The property parameters of materials are shown in Table 1 [6].

\subsection{Finite Element Model}

Using finite element analysis software ANSYS, the grid division of brake disc and friction plate are carried out respectively by sweep mode. The finite element model after grid division is shown in Fig. (2). In the figure, the brake disc is divided into 6000 elements and 7800 nodes, and the friction plate is divided into 320 units, 495 nodes.

Then, the boundary conditions and load are determined. Under the same conditions, the simulation calculation and comparative analysis of temperature field, thermal strain and stress field are carried out in two kinds of friction plates with different materials in the process of braking.

\subsection{Determination of Boundary Condition}

Assume that the initial velocity is $120 \mathrm{~km} / \mathrm{h}$, the radius of contact surface is the average value between the inner radius and the outer radius of friction plate, the braking process is uniform deceleration motion, the braking deceleration is $4.95 \mathrm{~m} / \mathrm{s}^{2}$, and the slip rate between tire and road is taken as 0.1 . Then, according to Eq. 6, the function relationship between heat flux and braking time can be obtained easily.

Table 1. Property parameters of materials.

\begin{tabular}{|c|c|c|c|}
\hline Property Parameters & Brake Disc & Friction Plate 1 & Friction Plate 2 \\
\hline \hline Density, $\mathrm{kg} \cdot \mathrm{m}^{-3}$ & 7228 & 2595 & 2343 \\
\hline Thermal conductivity, $\mathrm{W} /\left(\mathrm{m} \cdot{ }^{\circ} \mathrm{C}\right)$ & 48.46 & 1.212 & 1.4 \\
\hline Specific heat, $\mathrm{J} /\left(\mathrm{kg} \cdot{ }^{\circ} \mathrm{C}\right)$ & 503 & 530 & 1400 \\
\hline Modulus of elasticity, $\mathrm{p}_{\mathrm{a}}$ & $1.05 \mathrm{e} 11$ & $9.5 \mathrm{e} 10$ & $1.16 \mathrm{e} 11$ \\
\hline Poisson ratio & 0.3 & 0.3 & 0.3 \\
\hline
\end{tabular}




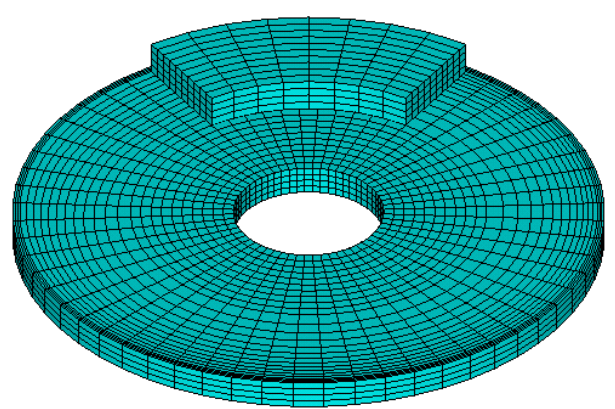

Fig. (2). Finite element model of brake.

In the process of braking, the empirical formula of the transfer coefficient of heat convection of disc brake is as follows.

$h= \begin{cases}0.70(k / D) \mathrm{R}_{\mathrm{e}}^{0.55} & \mathrm{R}_{\mathrm{e}} \leq 2.4 \times 10^{5} \\ 0.04(k / D) \mathrm{R}_{\mathrm{e}}^{0.80} & \mathrm{R}_{\mathrm{e}}>2.4 \times 10^{5}\end{cases}$

where $\mathrm{D}$ is the outer diameter of brake disc, $\mathrm{R}_{\mathrm{e}}$ is the Reynolds number.

$\mathrm{R}_{\mathrm{e}}=\omega R \rho_{a} / u_{a}$

where $\omega$ is the angular velocity of brake disc, R is the rolling radius of tire, $\rho_{a}$ is the air density and its value is taken as $1.13 \mathrm{~kg} / \mathrm{m}^{3}, u_{a}$ is the air viscosity and its value is taken as $1.91 * 10^{-5} \mathrm{~kg} / \mathrm{m}$, and $\mathrm{k}$ is taken as $0.0276 \mathrm{~W} /\left(\mathrm{m} \cdot{ }^{\circ} \mathrm{C}\right)[6]$.

\subsection{Solving Process}

Because the temperature and stress of friction plate and brake disc are changed by friction in the process of braking, the transient analysis model of thermal structure coupling is elected as the type of finite element analysis. In the thermo- dynamic boundary conditions, there are both the heat flux density caused by friction and the heat loss through convection in the air when the brake stops [7].

Therefore, the boundary conditions, including environment temperature, heat flux density and transfer coefficient of convection heat, are defined firstly in the simulation. Among them, the initial temperature of the environment is $20{ }^{\circ} \mathrm{C}$. Secondly, the load step options are determined. The problem is solved according to two load steps. The first load step is determined to apply heat flux density to the contact point between brake disc and friction plate with gradient method. The second load step is determined to apply transfer coefficient of convection heat to no contact surface between brake disc and friction plate in order to simulate the external convective constant load.

\section{RESULTS AND ANALYSIS OF SIMULATION}

Under emergency braking selected in this paper when the speed is $120 \mathrm{~km} / \mathrm{h}$, the temperature field and thermal stress field produced by the same brake disc and two kinds of friction plates of different materials are calculated respectively. And the simulation results are compared and analyzed.

\subsection{Simulation Results and Analysis of Temperature Field}

Through iterative calculation based on ANSYS, the simulation results of temperature field are obtained as shown in Figs. (3 and 4). It can be seen that the trends of temperature variation of the brake discs are similar from Figs. ( 3 and 4). The rise of temperature focuses on friction contact region, and the high temperature zone is in the middle position of contact area. With the progress of braking, the temperature distribution is more and more dispersed.

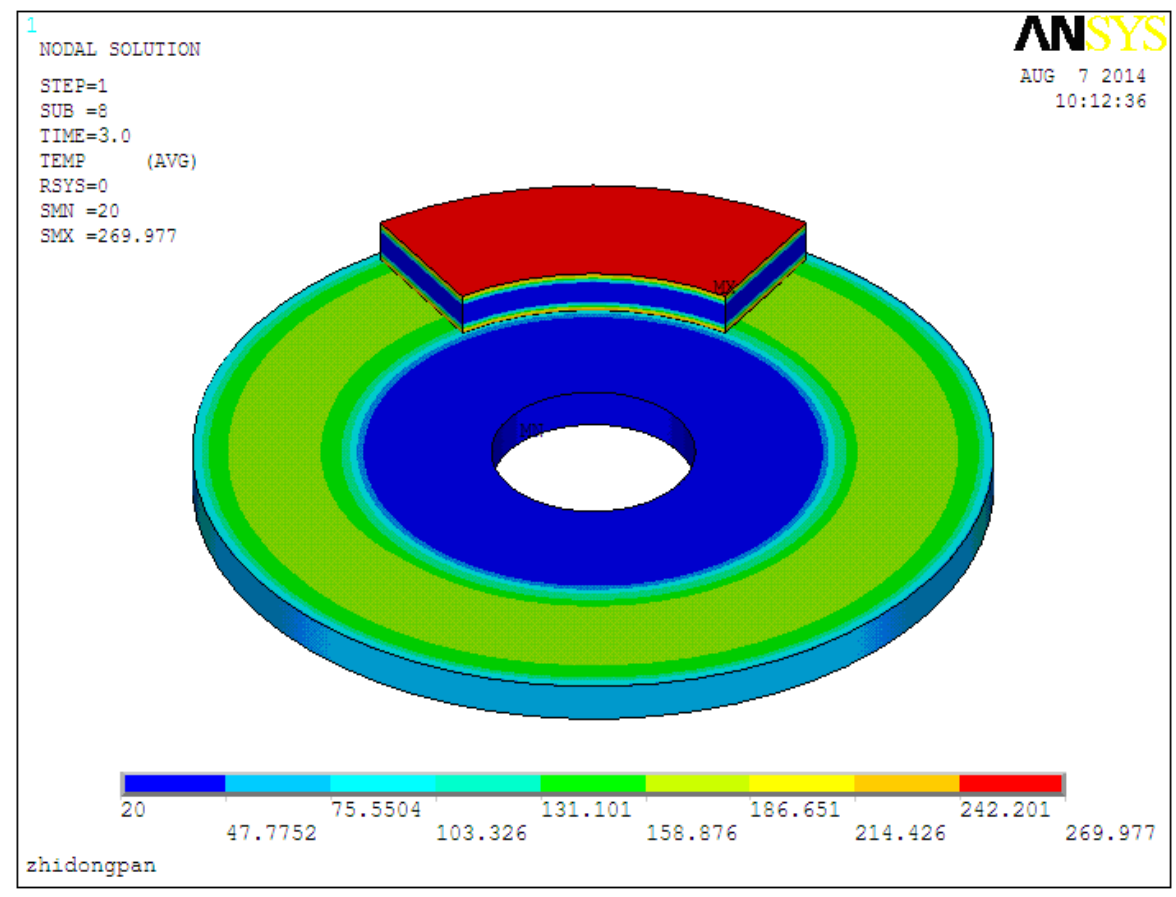

Fig. (3). Temperature field of brake 1. 


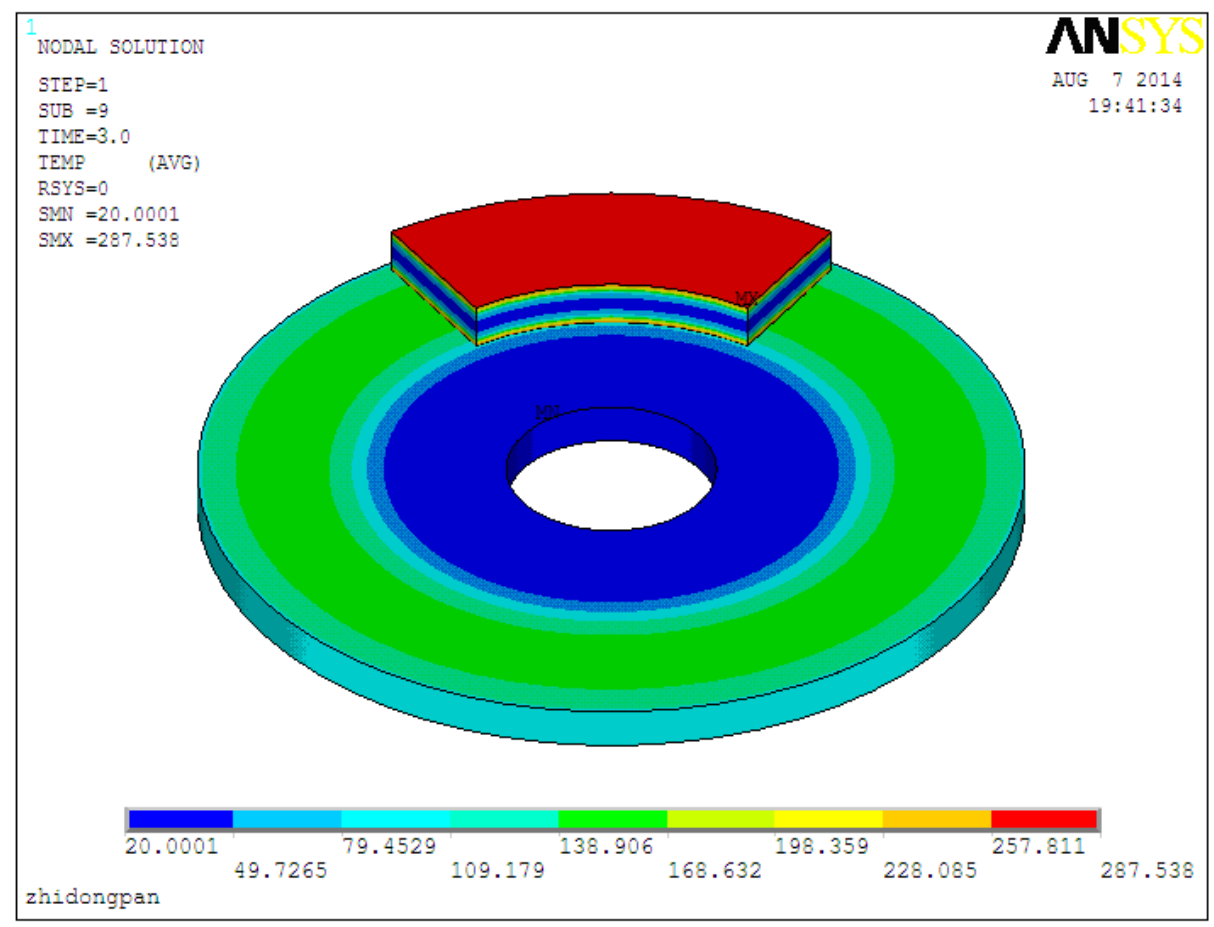

Fig. (4). Temperature field of brake 2.

The curves of temperature variation in the place where the radial size is $200 \mathrm{~mm}$ are shown in Fig. (5). The temperature of brake discs reaches the highest value at $3.4 \mathrm{~s}$, the maximum temperature of brake disc contacted with friction plate 1 is $260{ }^{\circ} \mathrm{C}$, and the maximum temperature of brake disc contacted with friction plate 2 is $290{ }^{\circ} \mathrm{C}$. This is because the heat conduction rate of friction plate 1 is higher than friction plate 2. After reaching the peak, the temperature of brake disc begins to decline slowly and gradually. The reason is that the friction heat absorbed by brake disc is even more greater than the diffusion heat of brake disc at the start, and with the decreasing speed, the heat flow density absorbed by brake disc decreases.

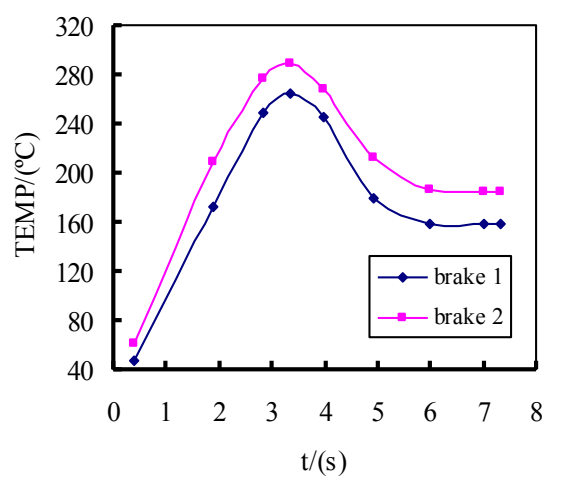

Fig. (5). Curves of temperature variation.

The temperature fields of friction plate 1 and friction plate 2 are shown in Figs. (6 and 7) respectively. It can be seen that the influence of friction heat on heat affected layer of friction plate is small, and only in the region near friction. The highest temperature is in the contact surface. With the increase of axial distance, the effect of friction heat is more and more weak.
The temperature distribution curves of friction plates under different axial thickness are shown in Figs. (8 and 9). At the start, the temperature of friction plate increases gradually, until it reaches the highest temperature, because the friction heat absorbed by friction plate is greater than the diffusion heat of friction plate. After reaching the peak, with heat transfer from friction plate to brake disc, the temperature of friction plate begins to decline slowly and gradually. It can be seen that the highest temperature of friction plate 1 is significantly less than the highest temperature of friction plate 2 . It is further proved that the thermal conductivity of friction plate 1 is better than friction plate 2 .

\subsection{Simulation Results and Analysis of Thermal Stress Field}

The temperature of each part of friction plate is changed because of friction heat and internal heat conduction, and uneven temperature changes will produce heat stress [8]. The process of thermal stress analysis includes: from transforming the temperature field model into a structural analysis model, importing the characteristic parameters of materials in the Table 1, applying symmetric boundary and displacement constraints for finite element model, loading the temperature value obtained by analysis step by step, to solving and calculating the thermal stress of brake disc. For the two kinds of materials, under the same conditions, the finite element simulation results of equivalent thermal stress in different locations are shown in Figs. (10 and 11).

From the thermal stress distributions, it can be seen that the maximum stress of friction plate 1 is $63.1 \mathrm{Mpa}$ and the maximum stress of friction plate 2 is $98.4 \mathrm{Mpa}$. This indicates that the friction plate 2 is more prone to creep crack under the same fatigue strength. 


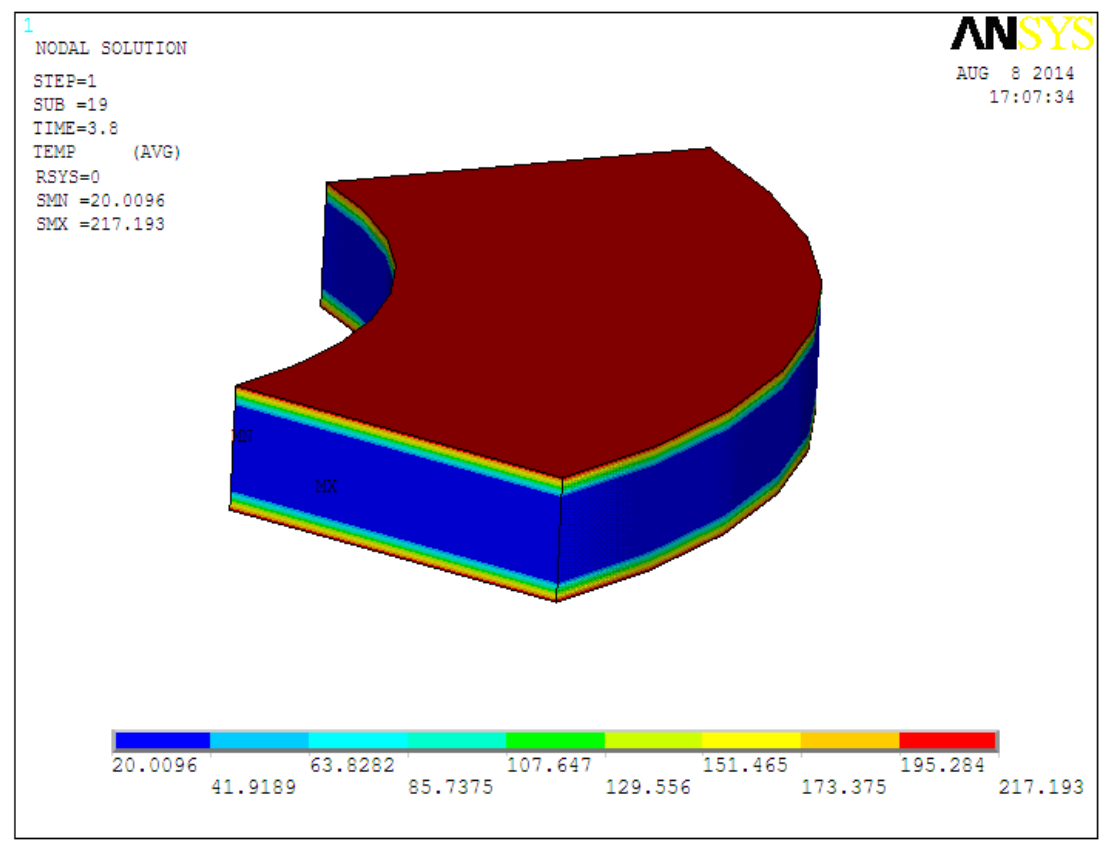

Fig. (6). Temperature field of friction plate 1.

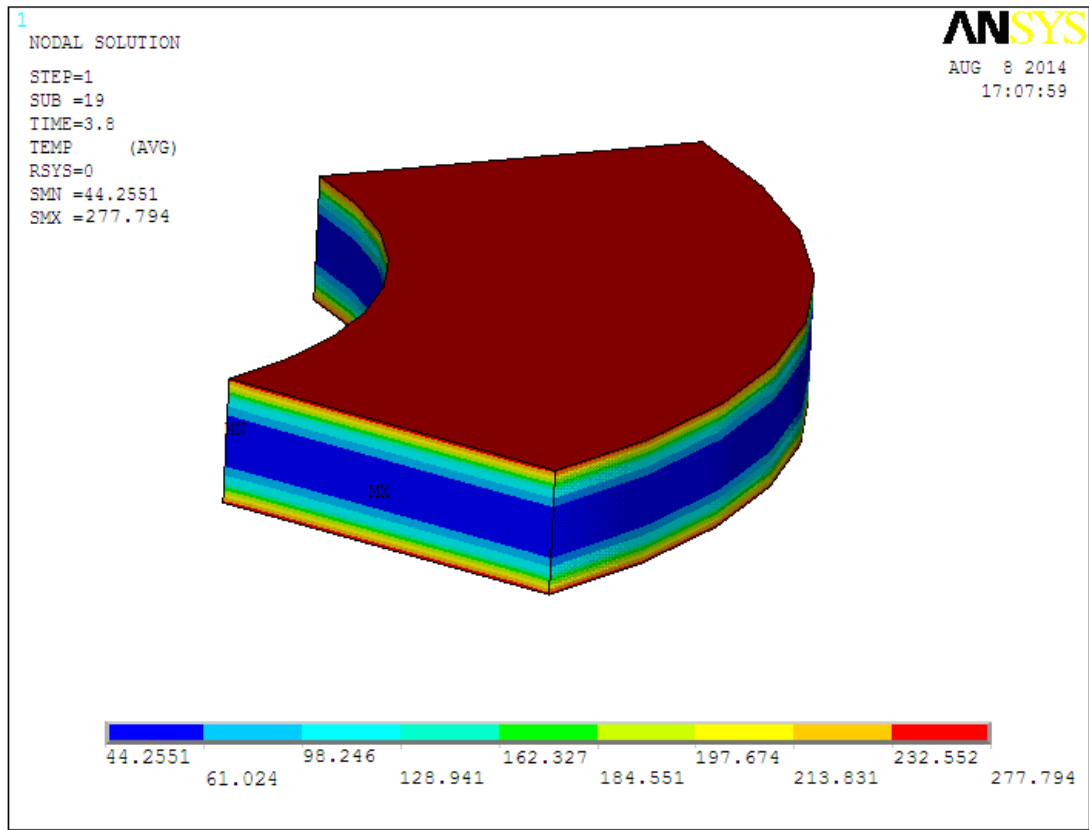

Fig. (7). Temperature field of friction plate 2.

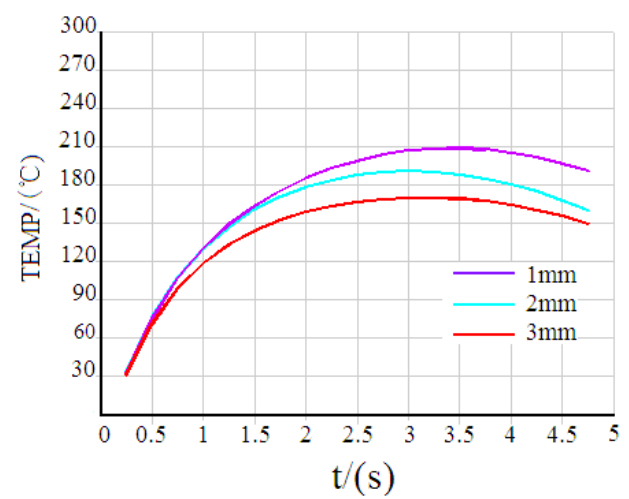

Fig. (8). Temperature distribution of friction plate 1 .

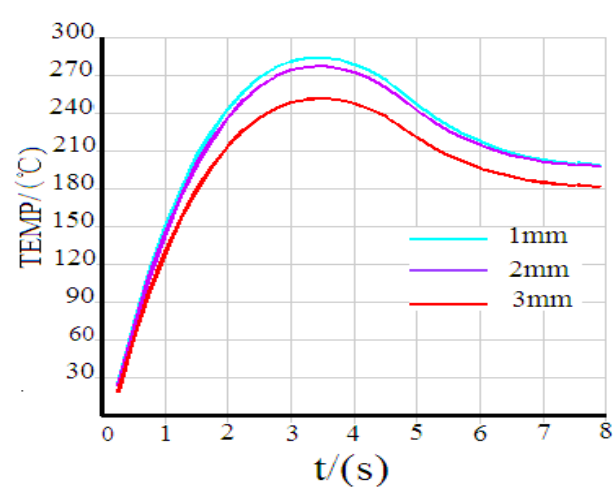

Fig. (9). Temperature distribution of friction plate 1. 


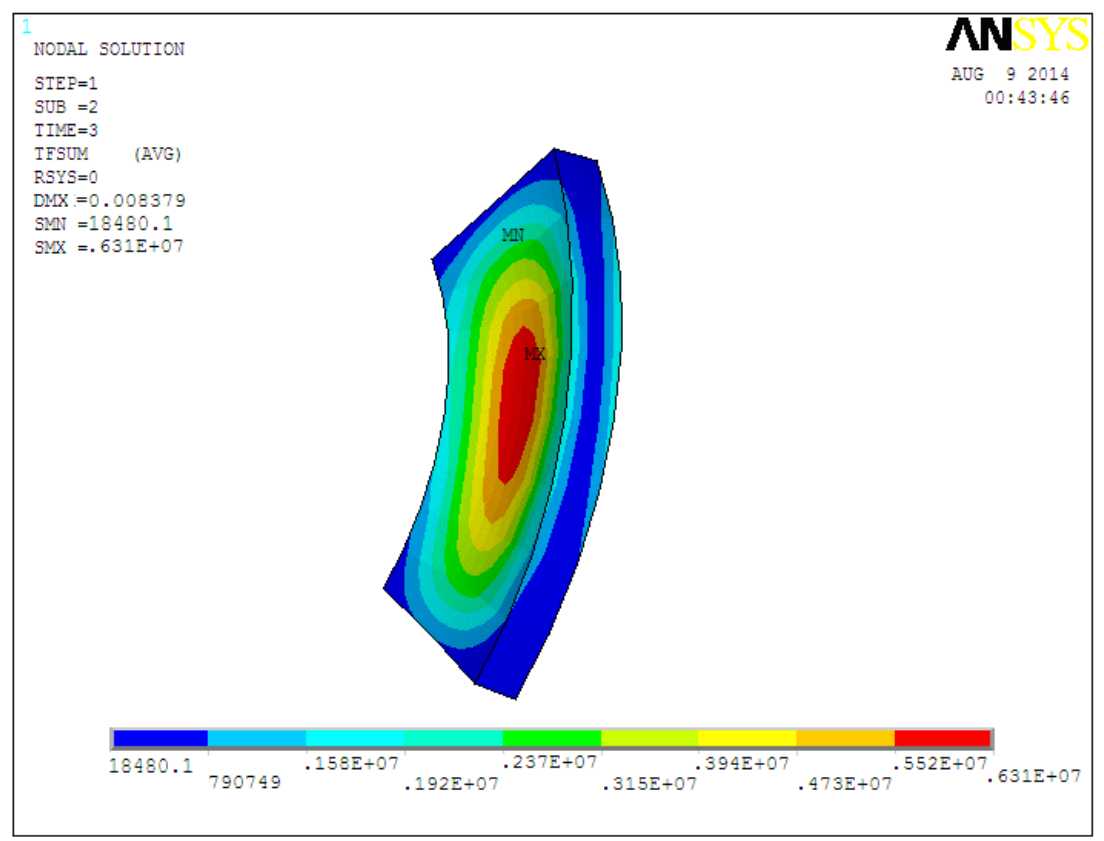

Fig. (10). Equivalent thermal stress of friction plate 1.

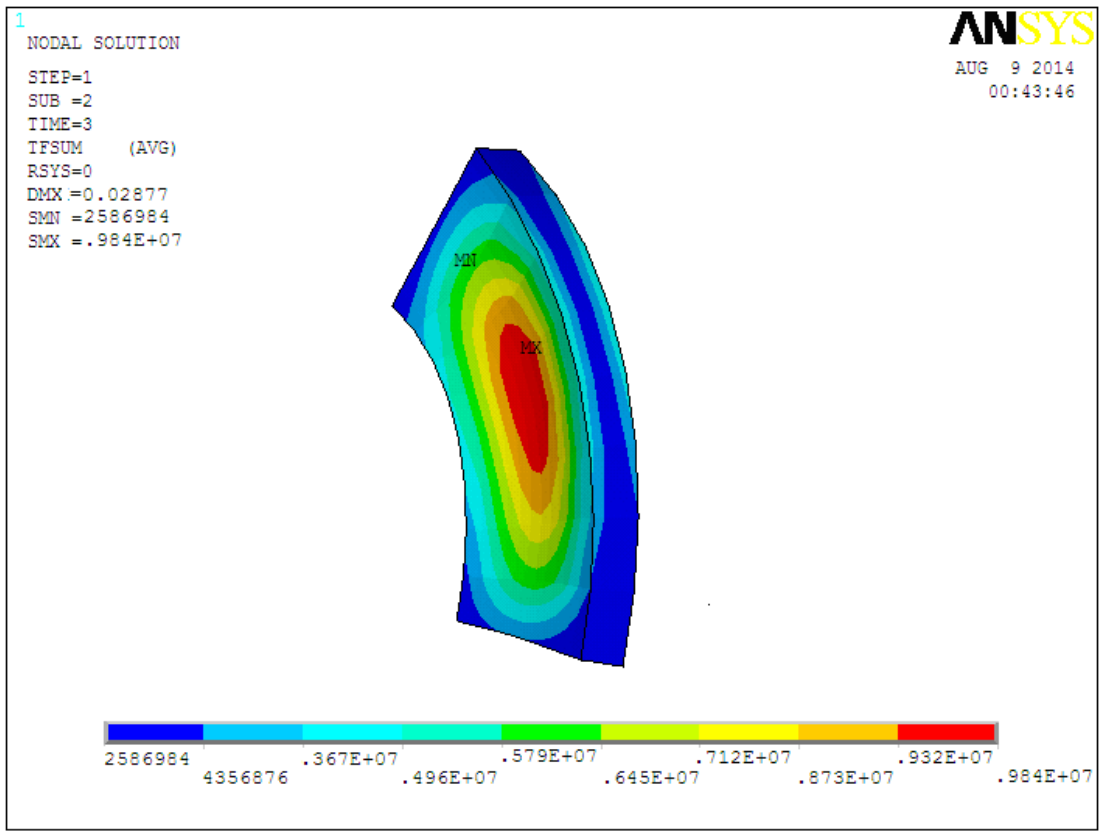

Fig. (11). Equivalent thermal stress of friction plate 2 .

\section{CONCLUSION}

Firstly, the numerical analysis methods of conversion and distribution of braking energy, distribution of friction heat, transfer of friction heat and thermal mechanical coupling, were established. Secondly, the geometric model of brake was created based on parameters of vehicle selected; the property parameters of friction materials were selected; the finite element models were obtained; and the solving process was determined. Finally, the temperature field and thermal stress field produced by the same brake disc and two kinds of friction plates of different materials, which are the composite materials based on resin and the powder metallurgy based on copper, were simulated and analyzed respectively under emergency braking. The results showed that the numerical simulation methods proposed had a good predictive effect on the typical characteristics of friction materials in the process of braking, and could provide effective references for preparation and optimization design of friction materials of brake.

\section{CONFLICT OF INTEREST}

The authors confirm that this article content has no conflict of interest. 


\section{ACKNOWLEDGEMENTS}

This research is supported by the University Science Research Project of Jiangsu Province (13KJB580005), the Jiangsu Province Ordinary University Graduate Research and Innovation Project (CXZZ13_0659), and the Open Fund Project of Automotive Engineering Key Laboratory of Jiangsu Province (QC201207).

\section{REFERENCES}

[1] Yu Zhisheng, Theory of Automobile, Mechanical Industry Press: Beijing, 2008.

[2] Chen Deling, ZHANG Jianwu, and ZHOU Ping, "FEM Thermal Stress Analysis of High-speed Locomotive Braking Discs", Journal of the China Railway Society, vol. 28, pp. 39-43, April 2006.
[3] Wang Yazhen, "Study on the mechanism of interfacial friction based on the thermal dynamics coupling", Ph. D. thesis, South China University of Technology, Guangzhou, CA, CHINA, June 1, 2010.

[4] Wang Shixian and XU Jiansheng, "Study on the thermal structural couple field of sliding friction process based on ANSYS", Journal of Wuhan Institute of Technology, vol. 5, pp. 67-71, May 2009.

[5] MO Yimin and WANG Feng, "Formal Analysis and Verification of Mini Vehicle Clutch Friction Pair's Temperature Field", Journal of Wuhan University of Technology, vol. 6, pp. 107-110, June 2010.

[6] Wu Jingsi, "Thermal structure coupled simulation and life research for automotive disc brake", M. S. thesis, Southwest Jiaotong University, CA, CHINA, April 2011.

[7] Yevtushenko A A and Grzes P, "The FEM-modeling of the frictional heating phenomenon in the pad/disc tribo system (a review)", Numerical Heat Transfer, vol. 3, pp. 207-226, March 2010.

[8] Su Haifu, "Thermal-mechanical coupled finite element analysis on disc brake", Ph. D. thesis, South China University of Technology, Guangzhou, CA, CHINA, June 1, 2011.

(C) Wang and Tang; Licensee Bentham Open.

This is an open access articles licensed under the terms of the Creative Commons Attribution-Non-Commercial 4.0 International Public License (CC BY-NC 4.0) (https://creativecommons.org/licenses/by-nc/4.0/legalcode), which permits unrestricted, non-commercial use, distribution and reproduction in any medium, provided that the work is properly cited. 